\section{Japan's frontiers research to cross international boundaries}

\section{Tokyo}

JAPAN's Human Frontier Science Program is at last taking shape but it is considerably smaller than originally planned. Nevertheless, if Japan can win support from the governments of the other Western summit members (Canada, Britain, France, West Germany, Italy, the United States and the European Community), Frontiers could become a substantial international programme of research in the biosciences.

In 1984, the then Japanese Prime Minister, Yasuhiro Nakasone, first suggested that Japan should initiate an international bioscience project. Two years later, the Ministry of International Trade and Industry (MITI) and the Science and Technology Agency (STA) came forward with proposals — the Human Frontier Program and the Human and Earth Science Program - which were later fused into the Human Frontier Science Program.

It was widely reported that Frontiers would plough about $\$ 6,000$ million into international basic research in the biosciences over twenty years. But the programme has been bogged down in a prolonged feasibility study and the scale of the programme has been reduced.

Last week, scientists and science administrators from the seven summit nations and the European Community met in Tokyo to finalize conclusions of an "international feasibility study" which began in November. The committee in a draft report recommends that Frontiers should consist of international grants, fellowships and workshops. A council of about twenty scientists will select priority areas for research and topics for workshops, while review committees will screen applications for grants and fellowships.

Initially there will be two priority areas for research: "higher order functions of the brain" and "molecular recognition and response functions". According to the committee's recommendations, $30-50$ three year grants each worth an average of half a million dollars a year will be awarded annually to teams of researchers from two or more member nations. In addition, 100-200 two-year postdoctoral fellowships worth about $\$ 50,000$ each a year will be awarded annually and $10-20$ workshops will be held every year at a cost of about $\$ 100,000$ per workshop.

This brings the total annual budget for Frontiers (excluding administrative costs) to $\$ 60-100$ million. But it is still not clear where the money will come from.

MITI officials say they now have the "understanding" of the Ministry of Finance and a programme of the scale proposed is possible. But the other summit nations have yet to make any financial commitment to Frontiers and it would be unprecedented for Japan alone to finance an international programme of this scale. MITI and STA have only won a few million dollars for the programme in fiscal year 1988. But MITI is in a strong position to bargain for funds in the next fiscal year. The Finance Ministry, Prime Minister Noboru Takeshita and the ruling Liberal Democratic Party are keen to introduce a new indirect tax and MITI's support will be required to gain the "understanding" of Japanese businessmen. But no doubt some commitment on the part of other summit nations to join Frontiers would greatly strengthen MITI's hand.

Another critical test facing the pro-
Paris

SATURNE, a French synchrotron with a unique capability to accelerate polarized protons and deuterons, is now equipped with a low-energy accumulator booster synchrotron, MIMAS. Operational since October 1987, MIMAS was officially unveiled on 2 March at the Nuclear Research Centre (CENS) at Saclay, south-west of Paris.

Scientists at Saclay hope that MIMAS will allow Saturne to accelerate ions as heavy as krypton, as well as increasing the intensity of the polarized beams. After accumulation and acceleration, MIMAS can inject a particle beam at up to $47 \mathrm{MeV}$ for protons (11 MeV per nucleon for heavy ions) into the main synchrotron,

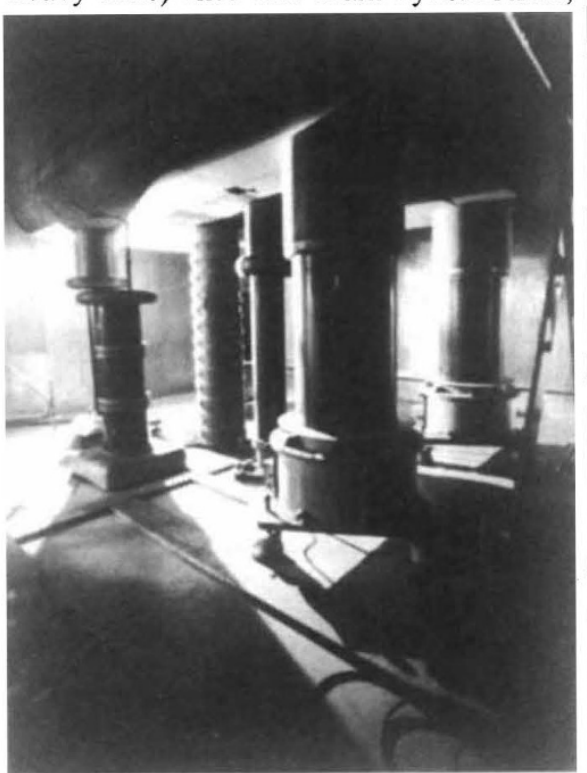

Isolation supports of Saturne's polarized particle source. gramme is the selection of scientists for the governing council and review committees. Sir John Kendrew, representing the European Community, proposed in last week's meeting that the seven summit nations and the Community should each nominate five scientists for the council. And then Japan as initiator (and financer?) of Frontiers should choose twenty of them. Although well received, this proposal would give the Europeans a disproportionately large say in the programme.

Time is running short. MITI and STA are keen that an international peer review system should be in place to distribute grants and organize workshops in fiscal year 1988 (which starts next month). The next Frontiers meeting will be held in Bonn on April 29 and the ministry and agency are clearly aiming at getting the programme off the ground before the next summit in Toronto.

David Swinbanks

\title{
Low-energy accumulator for the French Saturne synchrotron
}

Saturne, where energies up to $3 \mathrm{GeV}$ for protons and $1.1 \mathrm{GeV}$ per nucleon for heavy ions may be achieved.

"The problems of working at such low energies have scared off most laboratories", says Michel Oliver, of the Laboratoire Nationale Saturne (LNS) at Saclay. The principal problem, beam contamination by unwanted electrons, is overcome in MIMAS by heating the vacuum chamber to $300{ }^{\circ} \mathrm{C}$ and trapping electrons on a titanium sublimator.

Although the synchrotron is unable to attain the high energies necessary to work with heavy ions such as uranium, the wide range of available particles and the high quality of Saturne's spectrometers means that it is much in demand. Last year, out of 400 scientists using the facility, 270 came from abroad, with roughly the same number of projects having to be turned down. A cooperative research agreement has recently been signed with the GSI Laboratory at Darmstadt, West Germany, where a heavy-ion synchrotron is being built. A similar exchange is under discussion with the Italian National Nuclear Physics Institute.

The $£ 3.7$ million budget for Saturne is financed jointly by the French Atomic Energy Commission (CEA) and the Centre National de la Recherche Scientifique (CNRS). Foreign researchers do not have to pay for beam time in the laboratory.

MIMAS has provided another kind of spin-off. In collaboration with an industrial company, GEPE, the laboratory at Saclay has recently patented the highprecision electronic relay it invented as part of the technological development for the new synchrotron. 